\title{
O ESPAÇO POLÍTICO DA LÍNGUA ESPANHOLA NO MUNDO
}

\section{THE POLITICAL DOMAIN OF THE SPANISH LANGUAGE IN THE WORLD}

\author{
Xoán Carlos Lagares*
}

\section{RESUMO}

Este artigo aborda o processo histórico de construção do espaço político da língua espanhola no mundo. Diferentemente do acontecido com outras línguas europeias, esse espaço começou a se constituir já no século XVI, com a expansão política dos reinos ibéricos. As peculiares condições sócio-históricas nos diversos lugares da América Latina, assim como os desiguais processos de padronização, explicam a diversidade do espanhol falado no continente. Do ponto de vista normativo, o espaço da língua espanhola se caracteriza pela tensão entre um evidente pluricentrismo e a tentativa de constituição de um único centro na Espanha, representado nos instrumentos normativos elaborados pela Real Academia Española. Essa tentativa de controle deu origem a uma política pan-hispânica nos anos 90, caracterizada pela aceitação tutelada da diversidade e pela ênfase no valor econômico da língua. Atualmente, novas iniciativas padronizadoras e econômicas surgidas na América Latina começam a configurar uma nova realidade na gestão internacional do espanhol.

Palavras-chave: política linguística; hispanismo; padronização.

\section{ABSTRACT}

This article deals with the historical process of constructing the political domain of the Spanish language in the world. Unlike other European languages, this space had already begun to be established in the sixteenth century with the political expansion of the Iberian kingdoms. Both the particular sociohistorical conditions in the different regions of Latin America and the unequal standardisation processes account for the diversity of the Spanish varieties spoken in that continent. From a normative perspective, the domain of Spanish is defined by tension between a clear pluricentralism and an effort to constitute a sole centre in Spain, reflected in the normative instruments developed by the Real Academia Española. This attempt at control gave rise to a pan-Hispanic policy in the 1990s, featuring a tutelary acceptance of diversity and emphasis on the language's economic value. At present, new initiatives, both standardising and economic, that have emerged in Latin America are beginning to shape a new phase in the international management of Spanish.

Keywords: language policy; hispanism; standardization.

\footnotetext{
* UFF, Rio de Janeiro (RJ), Brasil. xlagares@id.uff.br
} 


\section{DIVERSIDADE LINGUÍSTICA E FONIAS}

A realidade das línguas do mundo é complexa. Não sabemos exatamente quantas línguas são faladas no planeta e nem temos critérios claros e objetivos que nos permitam diferenciar variedades estruturalmente próximas e decidir, sem discussão, se duas falas "aparentadas" constituem ou não a mesma língua. O próprio carácter social e cultural do objeto "língua" (que, como todo objeto cultural, tem uma história) faz com que seja impossível reconhecer e delimitar idiomas sem levarmos em conta as condições sociopolíticas e históricas das comunidades que os falam. Enquanto objetos de estudo, ou mesmo como matéria de discussão, eles são construídos discursivamente em condições históricas concretas, por meio de complexas representações sociais inseridas nas mais diversas relações de poder. Os falantes veem suas práticas condicionadas por essas representações, pelo carácter performativo de determinadas ideologias linguísticas e por intervenções diretas dos poderes políticos sobre a realidade social da linguagem (VALLE, 2013, p. 18-19).

Por esse motivo, ao pensarmos as relações entre línguas no espaço mundial, devemos prestar atenção nas relações entre os falantes, no modo como eles interagem entre si, com falantes da sua mesma língua e de outros idiomas. Essas relações são mediadas, por sua vez, por todo tipo de representações em torno de ideias de beleza, utilidade, identidade, representatividade etc, e mesmo por interdições sociais que têm a ver com os âmbitos de uso, as funções comunicativas ou os gêneros discursivos implicados na utilização de uma ou de outra língua. Assim, por exemplo, as "escolhas" de uso de falantes bilíngues, em situações de línguas em contato, estão condicionadas por toda uma história de coerções sociais construídas na relação entre grupos humanos e pelas relações de poder existentes.

Seguindo o esquema proposto por Abraam de Swaan para compreender, do ponto de vista da sociologia e da economia política, as relações entre as línguas, Louis-Jean Calvet (2004, p. 78-84) propõe uma descrição da realidade linguística do mundo como um grande sistema gravitacional. Nessa galáxia, o inglês, ocupando o centro da constelação, seria a língua hipercentral, existiria uma dezena de línguas supercentrais (árabe, russo, suaíli, francês, hindi, espanhol, português, chinês...), uma ou duas centenas de línguas centrais (wolof, bambara, quíchua, checo, armênio...) e por volta de quatro ou cinco mil línguas periféricas.

O "cimento" que une essas línguas, pondo em relação os diversos níveis do sistema linguístico gravitacional, seria o bilinguismo. Para Calvet, seria necessário ainda diferenciar, por um lado, entre aquele bilinguismo que é produto de aprendizagem programada e o que surge da aprendizagem espontânea, e por outro lado, 
o bilinguismo horizontal e o vertical, segundo a aprendizagem tenha como objeto uma língua do mesmo nível ou de um nível superior ou inferior. Desta maneira, os falantes da língua hipercentral manifestam uma forte tendência ao monolinguismo; os das línguas supercentrais, ao bilinguismo horizontal e ao vertical com o inglês; os das línguas centrais, ao bilinguismo vertical com as supercentrais; e, finalmente, os falantes das línguas periféricas seriam autênticos poliglotas, com uma forte tendência ao plurilinguismo horizontal e vertical.

No sistema gravitacional assim desenhado, entende-se que todos os idiomas, menos os periféricos, constituem um centro em torno do qual giram outras línguas, exercendo algum tipo de atração sobre elas. Por exemplo, mesmo considerando que todas as línguas girem, de algum modo, em torno do inglês, uma língua central como o quíchua giraria primeiramente em torno do espanhol, naqueles territórios em que essa é a língua oficial e socialmente hegemônica. Isso significa que os falantes de quíchua bilíngues serão também falantes de espanhol, e não de qualquer outra língua supercentral. Em muitos casos, isso também supõe que a aprendizagem de outras línguas supercentrais, ou do próprio inglês, se realiza com instrumentos que provêm igualmente do espanhol, autêntica ponte por onde os falantes de quíchua devem transitar para poder aceder a outras realidades linguísticas.

Resulta evidente, portanto, que, do ponto de vista social, não todas as línguas têm o mesmo valor, nem o mesmo peso no sistema linguístico mundial. E isso não depende apenas do número de falantes que as utilizam, mas de diversos critérios relacionados à presença da língua no mundo, nos mais variados âmbitos de uso. O chinês mandarim, por exemplo, apesar de ser a língua com mais falantes, tem pouca extensão territorial, há poucas pessoas que a utilizam como língua adicional ou veicular, e é língua oficial de poucos países. Na realidade, umas poucas línguas da Europa, onde se concentram 3\% das línguas do mundo (enquanto Ásia e África reúnem $63 \%$ delas), são as mais faladas e as que estão mais estendidas geograficamente. Apesar da enorme quantidade de línguas faladas no planeta (por volta de 7.000$)$, 95\% delas são usadas por apenas $5 \%$ da população mundial (CALVET, 2012, p. 56). Louis-Jean Calvet criou um barômetro considerando dez fatores para quantificar o peso relativo das línguas: número de falantes, número de países nos quais a língua tem status oficial, número de artigos na Wikipédia, número de prêmios Nobel de literatura, entropia (definida em relação ao modo como os falantes se repartem na área ou áreas em que a língua é falada), taxa de fecundidade, índice de desenvolvimento humano, número de traduções e número de versões (CALVET, 2012, p. 60-61). A escolha dos critérios para mensurar o "peso" das línguas pode ser discutível, e o próprio uso de termos tomados do âmbito científico da física 
pode ser questionado, ao aparecer como um recurso discursivo de naturalização da desigualdade, mas é inegável que com essa abordagem o autor francês fornece um indicador que ajuda a conhecer a realidade linguística do mundo, e que pode servir de base para a formulação e adoção de políticas linguísticas no plano internacional. Ao estarem todas as línguas do mundo relacionadas,

\footnotetext{
agir sur l'une, c'est aussi agir sur les autres. Toute modification du comportement d'une langue par rapport à un facteur peut modifier la place d'une autre langue ou de plusieurs autres langues dans le classement, et comme ce type de modification peut relever de l'action humanie sur la langue c'est-a-dire d'une politique, s'ouvrent ainsi de nouvelles perspectives pour la politique linguistique. (CALVET, 2012, p. 72)
}

As fonias (francofonia, hispanofonia, lusofonia, anglofonia, arabofonia...), que podemos definir como espaços de gestão internacional de línguas, apresentam características diversas de acordo com sua história sociopolítica. Oliveira (2013, p. 65-66) compara quatro delas de acordo com a centralidade ou não da norma, e o papel que nela cumpre o Estado colonial e sua relação com o mercado na promoção da língua. Assim, a anglofonia teria uma norma descentralizada, sem protagonismo da antiga potência colonial e com um mercado forte; a francofonia e a hispanofonia teriam uma norma centralizada com grande protagonismo do antigo Estado colonial e forte intervenção econômica em sua difusão; enquanto a lusofonia teria uma norma descentralizada e dual, com pouca e desigual participação dos seus principais Estados - Portugal e Brasil - em sua promoção internacional.

\section{AS FONIAS E O ESPAÇO HISPÂNICO}

Definir as fonias simplesmente como espaços de comunicação internacional resulta demasiado impreciso, porque seria necessário determinar, previamente, a que tipo de comunicação nos estamos referindo, e como ela acontece em cada caso concreto. Preferimos entendê-las, em primeiro lugar, como produtos de processos históricos de expansão política e/ou religiosa. As línguas mais faladas do mundo, como vimos, concentram $95 \%$ da população mundial, e são na sua maioria de origem européia, de maneira que nesses casos é a expansão colonizadora do continente europeu que justifica a sua difusão. Para as fonias existirem como tais é preciso haver territórios "cobertos" pela hegemonia política e social de uma língua, na qual os falantes dos outros idiomas se encontrem em situação de minorização linguística. 
A primeira a receber tal nome, a francofonia, serviu de modelo para a formação de termos com o mesmo sufixo em outros espaços linguísticos. Caracteriza-se pelo forte peso que exerceu a potência colonial na definição de seu rumo, estendendo o padrão centralizador francês, cujo modelo serviu também de referente político para todos os estados nacionais modernos, para além das próprias fronteiras da nação. Estabelece assim uma nova relação centro-periferia, em que o imaginário normativo se reproduz numa escala que ultrapassa o território da França e se estende a todos os países colonizados por ela. Como diz Pierre Guisan, chega a operar-se no âmbito discursivo uma separação, em enunciados emitidos na antiga metrópole, entre os países francófonos e a própria França: "Vistos desse país, portanto, os francófonos são os outros" (GUISAN, 2011, p. 146).

A expansão do francês está ligada ao sucesso do modelo da língua nacional e à sua difusão para além do território da nação, com a colonização europeia da África e da Ásia nos séculos XIX e XX. Mas a sua presença em instituições internacionais e o seu prestígio como língua de cultura tem a ver, sobretudo, com o papel que a França cumpriu desde cedo como centro mundial da cultura "leiga", e com o fato de Paris ser um centro cultural de produção e validação internacional da cultura letrada ${ }^{1}$.

O sucesso do inglês como língua de comunicação internacional também deve ser atribuído a outras circunstâncias históricas não só relacionadas com o processo de expansão colonial. Como resultado da colonização britânica, o inglês é língua primeira da maioria da população em países como os Estados Unidos, Canadá, Austrália, Nova Zelândia e África do Sul; mas é também língua oficial e, de fato, língua do poder em muitos estados da Ásia (Paquistão, Bangladesh, a Índia) e da África, em que os falantes de inglês são minoria. Porém, a hegemonia internacional do inglês se baseia principalmente no fato de outros países se situarem na sua órbita, apesar de não o terem como língua primeira da sua população nem como língua oficial, ao utilizarem o inglês como principal idioma de relação internacional. Acontece isso em países como a China, Egito ou os Emirados Árabes (que foram pro-

\footnotetext{
2 Como explica Pascale Casanova (2002, p. 93): “Essa inversão da dominação cultural em proveito do francês como língua da "civilização", como os alemães dirão alguns anos mais tarde, funda, portanto, uma nova ordem européia: "uma ordem internacional leiga". Essa laicização geral do espaço político e literário europeu, que é um dos traços constitutivos da ascendência do francês, é a consequência última do empreendimento inaugurado por Du Bellay e do humanismo contra a influência do latim. Nesse sentido, é possível compreendê-la como um primeiro movimento rumo à autonomia do conjunto do espaço literário europeu que desta forma escapava definitivamente à ascendência e à dominação da Igreja".
} 
tetorados britânicos) ou em pequenos estados independentes como os países escandinavos ou os Países Baixos. Mas o grande sucesso do inglês como "língua franca" nas relações internacionais (políticas, econômicas, culturais, científico-acadêmicas) se deve ao enorme poder de atração do mercado de bens materiais constituído nessa língua². Como afirma Jean-Marie Le Breton, com cauteloso triunfalismo liberal:

\begin{abstract}
O inglês teve uma geopolítica relativamente simples, para todos os efeitos, comparável à do francês. De língua nacional, ele se tornou imperial. E tende a tornar-se universal, e não apenas por uma questão de geografia. Ele aspira manifestamente a se tornar a língua do progresso, da ciência, da pesquisa; a língua da inovação, da conquista material; a língua da riqueza; a língua dos homens que são seguros de si e que podem ser tomados como modelo, sem deixar de ser a língua do não-conformismo e da liberdade de espírito. Essa é a nova fase da progressão do inglês. Convém examinar em que medida o inglês poderá escapar à contradição que existe entre o anticonformismo das origens e as leis atuais do triunfo material. (LE BRETON, 2005, p. 21)
\end{abstract}

Por outro lado, enquanto realidades sociais reconhecíveis, as fonias funcionam pela constituição de "comunidades discursivas" que categorizam a língua e a cultura de formas particulares. Vimos como o francês era categorizado como a língua da "cultura leiga", frente à cultura religiosa representada pelo latim; assim como o inglês é apresentado como a língua dos "homens livres". Essas comunidades discursivas que falam (d)a língua também se configuram como palcos ou arenas em que se dirimem interesses contrapostos, numa dimensão polêmica. No caso do espanhol, José del Valle estabelece uma clara diferença entre o conceito de bispanismo ou bispano-americanismo, que é como se denomina tradicionalmente na Espanha, desde o século XIX, o movimento cultural destinado a desenvolver uma consciência comunitária compartilhada com as antigas colônias, e o de bispanofonia, que ele define como uma ideologia linguística, um sistema de ideologemas "en torno al español historicamente localizado que concibe el idioma como la materialización de un orden colectivo en el cual España desempeña un papel central" (VALLE, 2007, p. 37-38). Nesse sentido, este autor presta atenção ao modo como essa comunidade linguística se imagina como tal (apoiando-se no conceito de "comunidade imaginada" de ANDERSON, 2008), ao perfil que lhe dão as instituições responsáveis pelas políticas linguísticas nesse espaço, e também aos discursos que veiculam essas instituições e aos atores mais relevantes que nele participam.

2 David Crystal (2006, p. 23-33) enumera dez domínios em que o inglês se tornou preeminente, como consequência do poder dos Estados Unidos da América: a política, a economia, a imprensa, a propaganda, a radiodifusão, o cinema, a música popular, as viagens internacionais e a segurança, a educação e as comunicações. 
Diferentemente do que acontece no caso francês, de onde se criou o termo francofonia, que hoje funciona normalmente nos discursos das instituições responsáveis pela sua gestão (com particulares deslizamentos de sentido, como vimos), no caso do espanhol esse termo com o sufixo -fonia não tem tradição de uso, pois o seu lugar como noção delimitadora do espaço político do espanhol foi ocupado historicamente pelo de bispanidade, que adotou sentidos mais amplos. Isso constitui, de nosso ponto de vista, uma importante característica diferencial do espaço político internacional da língua espanhola, e tem consequências no modo como este é concebido.

Como é sabido, esse extenso espaço político do espanhol (assim como o do português) começa a se constituir historicamente muito antes que o dos outros idiomas europeus, já no século XVI, quando começa a expansão política fora da Europa dos estados ibéricos. É claro que a difusão, de fato, da língua espanhola nesse momento histórico é muito desigual, como tentaremos mostrar na continuação, e que os discursos que constróem a ficção da língua comum aparecem sobretudo a partir do século XIX, quando triunfa na Europa a ideia da língua nacional, necessariamente homogênea e estável, como principal instrumento de unidade política (MONTEAGUDO, 2013). Antes disso, a justificativa ideológica da colonização é religiosa, ligada à expansão do catolicismo, e a construção discursiva da unidade hispano-americana se centra, sobretudo, na "raça", mas numa noção de raça que valoriza a mestiçagem como um elemento determinante que teria dado lugar a uma nova realidade. Como explica Mauro Fernández (2007), a ideia da identidade mestiça surge como uma necessidade para as minorias "criollas", que lideram os processos de independência dos estados americanos, para imaginar um passado pré-hispânico que lhes dê identidade, mas sem ameaçar o ideal de continuidade cultural com a metrópole:

El mexicano Molina Enríquez (1909) nos aporta la que es tal vez la expresión más perfilada de la doctrina del mestizaje; y mestiza es también en su esencia la raza cósmica que teorizaba José Vasconcelos, esto es: "la raza definitiva, la raza síntesis o raza integral, hecha con el genio y con la sangre de todos los pueblos y, por lo mismo, más capaz de verdadera fraternidad y de visión realmente universal" (1925). En honor de esta raza cósmica mestiza se instituyó, como es bien sabido en el mundo hispano, la festividad de El Día de la Raza el 12 de octubre. (FERNÁNDEZ, 2007, p. 68)

Posteriormente, vai se operar, em relação ao castelhano, um deslizamento semântico da "língua da mestiçagem" para a "mestiçagem da língua" (Fernández, 2007, p. 69), mas a ideia do hispânico como produto da hibridação é muito antiga.

O termo "Espanha" é formado a partir de uma série sucessiva de apagamentos, que começa pela identificação exclusiva entre um dos Estados constituídos na 
Península Ibérica e o nome que todo esse território havia recebido dos colonizadores romanos: Hispania. Antes disso, na Idade Média, depois mesmo da formação do reino de Portugal, todos os habitantes da península eram denominados "espanhóis". Assim, na Crónica General de España do século XIII (que é uma crônica, exatamente, da Península Ibérica, e que servirá de base para a posterior Crônica Geral da Espanba de 1344, de D. Pedro, Conde de Barcelos, redigida em galego-português), encontramos a seguinte fala atribuída ao rei de Castela, Afonso X:

Desque los sus naturales ouo el rey don Alffonso puesto en recabdo desta guisa, apartosse otro día con los de Aragon et portogaleses et gallegos et asturianos, essos que y uinieron, et díxoles assí el rey don Alffonso: 'Amigos, todos nos somos espannoles [...]. (Afonso X, apud NIEDEREHE, 1985, p. 424)

Esse mesmo uso do termo aparece nada menos que no grande poema nacional português, do século XVI, Os Lusíadas, onde a "lusitana gente", isto é, o povo lusitano (segundo o sentido etimológico de 'gente', do gens, -tis latino), é qualificada como "gente fortíssima de Espanha":

O padre Baco ali não consentia

No que Júpiter disse, conhecendo

Que esquecerão seus feitos no Oriente

Se lá passar a Lusitana gente.

Ouvido tinha aos Fados que viria

Uma gente fortíssima de Espanha

Pelo mar alto, a qual sujeitaria

Da Índia tudo quanto Dóris banha,

E com novas vitórias venceria

A fama antiga, ou sua ou fosse estranha.

Altamente lhe dói perder a glória

De que Nisa celebra inda a memória (CAMÕES, 1988, p. 53).

Sem dúvida, a apropriação castelhana dos termos "Espanha" e "espanhol" explica-se pelo poder que adquire, nos séculos XVI e XVII, o reino de Castela e Aragão, sobretudo após a unificação ibérica, que acontece sob o comando de Castela. Nesse período histórico, as elites portuguesas são também bilíngues, o que permite entender que se identifique o castelhano como "língua vulgar da Espanha", como diz o anônimo autor da Gramática de la lengua vulgar de España, publicada em Louvain em 1559. Essa gramática afirmava que o castelhano era falado e entendido nos reinos de Aragão, Murcia, Andaluzia, Castela a Nova e a Velha, Leão e Portugal (ALONSO, 1979, p. 43-44). Poucos anos antes, um documento publicado na mesma cidade, em 1555, intitulado Útil y breve institución para aprender los principios y fun- 
damentos de la lengua española, justificava esta denominação "no porque en toda España se hable una sola lengua que sea universal, porque hay otras muchas lenguas, sino porque la mayor parte de España la habla" (ALONSO, 1979, p. 42), dando a enten-

der que nessa altura o castelhano funcionaria como língua dois (L2), pelo menos, para a aristocracia de todos os reinos ibéricos.

Pensamos, de qualquer modo, que seria anacrônico acreditar na efetiva difusão política de uma língua entre toda a população sob o domínio do reino naquele momento histórico, anterior ao da constituição da nação moderna, e que esse tipo de afirmação sobre a expansão do castelhano tem a ver com a simples desconsideração das outras línguas efetivamente faladas nesses reinos, e que não teriam na

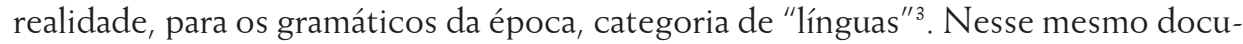
mento se esclarece que o idioma aí descrito devia se chamar propriamente "castelhano", por ser a língua da nação assim denominada, "que los romanos antiguamente contaban por Hispania Tarraconense" (ALONSO, 1979, p. 42)4.

As noções de "hispânico", "hispanidade" e "hispanismo", enfim, que condensam o sentido político atribuído à língua espanhola como garantia de unidade cultural, teriam se formado a partir de uma série de apagamentos e de exclusões, sempre contestados por visões alternativas que lutam contra a sua hegemonia. Como explicava Eduardo Subirats, numa conferência intitulada, provocadoramente, "Siete tesis contra el hispanismo", e que abriu o III Congresso Brasileiro de Hispanistas, realizado no Rio de Janeiro, em outubro de 2004:

la cristalización de lo hispánico en lo español, espina dorsal del discurso de la Hispanidad, se ha acompañado de una serie violenta de expulsiones y exclusiones lingüísticas y políticas, religiosas, intelectuales y étnicas, con efectos todavía vigentes hasta el día de hoy. Por eso el hispanista tiene que pensarlo dos veces antes de decidir si es hispánica la mística islámica de Al-Andalus, si pueden llamarse tales a los filósofos portugueses, judíos o conversos, exiliados en Ámsterdam en los siglos 17 y 18, o si es hispánica la Vanguardia Tropicalista de Salvador de Bahía, de raíces fundamentalmente africanas. (SUBIRATS, 2006, p. 15)

\section{COLONIZAÇÃO, DIVERSIDADE E NORMA(S)}

Para entender o modo como se constituiu o espaço político do castelhano seria preciso pesquisar como se produziu o processo de colonização em cada um dos

\footnotetext{
3 Desenvolvemos esta ideia em Lagares (2011, p. 175-183).

4 Obviamente, o conceito de nação mobilizado nessa fala do século XVI está relacionado ao seu sentido etimológico, "nascido num lugar concreto", e não ao sentido relacionado aos estados modernos, que surgem após a Revolução francesa.
} 
lugares do que viria a ser o mundo hispânico. Também seria preciso estudar como se construíram os imaginários linguísticos em relação à forma que foi adotando o idioma denominado castelhano nos diversos centros culturais da América.

Encontramos fundamentos para pesquisar a relação entre o desenvolvimento linguístico do espanhol nos diversos pontos da América Hispânica e a realidade sociopolítica desses territórios no livro de Bertil Malmberg, La América bispanobablante. Unidad y diferenciación del castellano, publicado, originariamente, em 1966, em idioma sueco. Apesar da perspectiva, muitas vezes, claramente eurocêntrica, adotada pelo autor na interpretação dos diversos cenários sociolinguísticos da América hispânica, esse livro tem o mérito de procurar explicações históricas e socioculturais para os fenômenos linguísticos, o que nem é tão comum nos trabalhos históricos sobre a língua espanhola, mais centrados na denominada "história interna" do que na integração entre as informações sócio-históricas e a descrição dinâmica dos sistemas linguísticos.

No capítulo 7, intitulado "La fragmentación lingüística de la América Hispana y sus principales centros culturales", Malmberg (1970, p. 145-146) estabelece alguns princípios para a descrição do processo de expansão histórica do castelhano em diversas áreas da América Latina, no que constitui, do nosso ponto de vista, um programa de trabalho ainda a ser desenvolvido integralmente. Esses princípios seriam os seguintes:

a) O estado político, social e cultural da população indígena à época da colonização.

b) A situação política e cultural de cada território durante a época colonial.

c) As relações entre povoadores europeus e indígenas americanos durante os primeiros séculos da colonização, e, sobretudo, a posição social desses últimos.

d) Os ideais linguísticos e culturais durante o século XIX.

e) A evolução linguístico-cultural posterior, sobretudo com o processo de industrialização e a imigração.

Segundo esses princípios, o autor identifica alguns centros culturais, delimitando áreas de influência com dinâmicas linguísticas próprias. Assim, por exemplo, a importância estratégica do Peru e de sua capital, Lima, durante o período colonial, corte de um poderoso vice-reinado, centro eclesiástico e onde se funda a primeira universidade da América do Sul, a Universidad de San Marcos, faz com que naquela capital vigore uma norma muito ligada à da metrópole castelhana. A importância da cultura incaica, falante de quíchua, em todo o território andino, no entanto, explica que a penetração do castelhano seja pequena e irregular. Nesse sentido, afirma o linguista sueco: 


\begin{abstract}
Muy cerca de la capital podemos encontrar indios que no entienden el español, hecho que pudo comprobar el autor durante una visita a las fantásticas ruinas de Cajamarquilla, una especie de Pompeya sudamericana con casas de barro, fortalezas, calles y murallas, que, según parece, estaba ya abandonada a la llegada de los conquistadores. El hecho de que en esta región el español se hable - cuando se habla - como una lengua extranjera, hace que la clasificación de su población como hispanohablante resulte incorrecta, tanto más que sigue empleando la estructura de su lengua nativa - lo cual suele suceder cuando sólo se toman elementos dispersos de un habla muy distinta de la propia y se hace, además, sin sistema alguno. (MALMBERG, 1970, p. 139)
\end{abstract}

O fato de Bogotá, a capital da Colômbia, ter se convertido num centro cultural de relevância para a sua área linguística apenas no final da época colonial, marcaria uma diferença a respeito do caso peruano, no que diz respeito à sobrevivência do elemento indígena. No caso colombiano, será em finais do século XIX, que a sua capital alcança o reconhecimento de "Atenas de Sudamérica", pelo trabalho padronizador de dois grandes humanistas, Miguel Antonio Caro (1843-1909) e José Cuervo (1844-1911), defensores da tradição clássica da língua espanhola. A vigência da difusão desse modelo de língua por todo o país, junto com a situação de pobreza econômica e miséria social das populações indígenas, teria uma grande influência na ausência de tendências normativas autonomistas.

O Chile representa também um marcado contraste com o Peru, dado que este país teria se mantido durante toda a época colonial como um "mero rincón del Imperio español" (MALMBERG, 1970, p. 141). Mais influído linguisticamente pela presença dos traços populares da imigração e, em boa medida, alheio à norma culta que chegava de San Marcos de Lima, a situação sociolinguística muda com a independência do século XIX e a aparição de um discurso purista, representado fundamentalmente pelo gramático Andrés Bello. Com efeito, como explica pormenorizadamente Arnoux (2008, p. 240-252), Bello, em sua Gramática de la Lengua Castellana destinada al uso de los americanos, publicada em 1847, expõe uma vontade codificadora que expressa também uma concepção estatal de língua. Uma das maiores preocupações de Bello será, precisamente, o risco de fragmentação do espanhol americano, de modo que o ensino da língua, segundo uma gramática caracterizada pelos atributos do estado nacional (autonomia, legitimidade, representatividade, centralização e racionalidade), será o melhor instrumento para construir a ideia da unidade linguística.

A influência indígena no Paraguai também é destacada no texto de Malmberg, que atribui à posição social de prestígio alcançada pelos índios paraguaios o desenvolvimento da língua espanhola nesse país, numa situação de bilinguismo bastante generalizado com o guarani. $\mathrm{O}$ mesmo autor destaca a evolução, em sentido oposto ao chileno, da norma linguística na Argentina, caracterizada desde cedo 
pelo seu marcado autonomismo. Com efeito, segundo Alfón (2008, p. 50-51), é a geração de intelectuais de 1837, representada por Echeverría, Gutiérrez e Alberdi, que potencializa a oposição linguística contra a Espanha, colocando o debate sobre unidade e variedade não na relação entre Buenos Aires e a província, mas entre Buenos Aires e Castela ou entre América e Espanha. Mas o ponto álgido da "querella de la lengua" nesse momento histórico está representado pela polêmica que se estabelece no Chile entre Sarmiento e Bello. Frente ao classicismo deste, aquele reivindica a independência linguística da América e chega a propor uma reforma ortográfica mais de acordo com as particularidades fonéticas das falas americanas.

Também é destacada por Malmberg, enfim, a influência indígena no espanhol mexicano, fundamentalmente na reivindicação de um passado azteca como elemento importante de identidade nacional. A presença de população africana, trazida como mão de obra escrava durante o período colonial, que deixou uma marca evidente na América Central, o efeito da desigual industrialização ao longo do século $\mathrm{XX}$ no território americano, e a chegada às vezes massiva de emigração espanhola, italiana ou portuguesa, são circunstâncias históricas que também deram lugar a configurações sociais com claras consequências na linguagem.

O resultado linguístico da colonização, em suas diversas fases e lugares, corresponde ao que Frago Gracía chama de "criollización", entendida não como a formação de uma nova língua surgida da mistura, mas como

\begin{abstract}
la alteración del español dialectalmente diferenciado llevado a América, base no ya fundamental, sino casi exclusiva, del fenómeno de regionalización lingüística que venimos considerando, a partir del cual surgió el español americano, nueva modalidad a su vez dotada de variedades socioculturales y geográficas menores, que no sólo se extendería a todos los criollos, o nacidos en Indias, sino que acabaría siendo asumida por éstos como rasgo distintivo de su personalidad americana. (FRAGO GRACÍA, 1999, p. 300)
\end{abstract}

Esse processo, que corresponderia a uma primeira fase de formação do espanhol americano, durante o período colonial, é descrito por De Granda (1994: 61) em termos de koineização, pois a partir de uma enorme heterogeneidade linguística causada pelo deslocamento de variedades diatópicas e diastráticas da metrópole, e do contato com outras línguas, teria acontecido a "cristalização" de uma modalidade linguística comum. Embora processos de confluência em centros coloniais deem lugar a formas de nivelação linguística, haveria que se questionar, de nosso ponto de vista, a visão homogeneizadora que o termo "koinè" evoca, sobretudo quando referido a todo o continente americano. O que teria se formado, sem dúvida, seriam variedades locais ou regionais mais ou menos reconhecíveis e estáveis, como resultado de formas próprias de regulação linguística endógena (POCHE, 1989: 73). 
A segunda fase de desenvolvimento do espanhol americano, segundo De Granda, que a considera finalizada em linhas gerais com a independência das nações hispano-americanas, teria características muito diferentes da primeira. Nesse momento, as mudanças mais importantes são causadas pela irregular padronização, que

\footnotetext{
no sólo no está presente en la totalidad de las áreas geográficas hispanoamericanas, sino sólo en alguna de ellas sino que, además, la misma actúa, en dependencia de factores causales altamente complejos y variables, en períodos cronológicos no contemporáneos respecto a diferentes zonas territoriales. (DE GRANDA, 1994, p. 61)
}

De alguns desses fatores complexos falamos esquematicamente, mostrando como as circunstâncias históricas vão configurando uma situação de efetivo pluricentrismo, com diversos centros culturais que produzem e difundem normas linguísticas.

\section{ENTRE PLURICENTRISMO E PAN-HISPANISMO}

É comum nos estudos sociolinguísticos definir a norma linguística em oposição ao conceito de variedade padrão. A norma seria, como a define Coseriu (1979), aquilo que está entre o sistema, conjunto de possibilidades estruturais do idioma, e o uso concreto individual da língua: uma série de regularidades no uso da língua de uma determinada comunidade, detectável através da pesquisa empírica realizada pelos linguistas. O padrão, contrariamente, constitui uma variedade artificial, construída pela ação consciente de gramáticos e dicionaristas, que propõem um modelo de língua baseado numa certa tradição prescritiva (ou contra ela). Essa distinção fundamental permitiria discriminar claramente entre o "normal", no sentido de usual, e o "normativo", entendido como prescritivo.

Alan Rey (2001) considera necessário ainda reconhecer a existência de normas subjetivas e avaliações sobre os usos emitidas pelos falantes em situações de interação comunicativa. Porém, todas essas noções encontram-se demasiado interligadas para que seja possível efetuar cortes epistemológicos rotundos. Por um lado, existe uma clara interdependência entre práticas e representações, que se influenciam mutuamente. Por outro, se a "norma objetiva" é apreendida através do trabalho dos linguistas, e emerge como consequência de um determinado ponto de vista focado na identificação do sistema da língua, para a maioria dos falantes o que existe realmente é uma rede complexa de normas "subjetivas", de juízos de valor a condicionar o uso efetivo que eles fazem da própria língua. Essas avaliações estão motivadas também, em boa medida, pelos padrões propostos e impostos politica- 
mente num determinado território. E, finalmente, o imaginário social identifica com frequência esse padrões artificiais com a norma objetiva, ou a língua-em-si.

Não apenas as normas cultas, entendidas como as regularidades do uso linguístico da população com maior nível de letramento, são variáveis e apresentam consideráveis diferenças regionais; a própria variedade padrão também se encontra em variação. E isso não apenas em relação às diversas normas que existem ao largo do mundo hispânico, mas também dentro de cada uma das comunidades linguísticas que conformam o espaço do espanhol no mundo, por causa das pressões sociais, os conflitos de interesses e as interpretações discordantes sobre o que seria ou deveria ser a prescrição mais adequada em cada caso concreto.

No espaço do espanhol, diversos centros de prestígio, ou grandes capitais econômicas e políticas, difundem normas próprias em suas áreas de influência (FONTANELLA DE WEINBERG, 1992). Como diz Adrián Fanjul:

\begin{abstract}
As formas em variação que se consagram como prestigiosas no seu raio de influência correspondem aos usos dos setores de maior peso nos campos cultural e econômico. De cidades como Buenos Aires, Bogotá, México, Lima, Santiago, Caracas ou Madri impõem-se, com grande participação da escola e da mídia, modos de falar regionalmente percebidos como "cultos", considerando aqui regiões amplas, que em vários casos ultrapassam as fronteiras de um só país. (FANJUL, 2011, p. 304)
\end{abstract}

Numa situação assim, os mesmos traços linguísticos podem receber diferentes valorações sociais em pontos diversos da América de língua castelhana. Um fenômeno como o "voseo", por exemplo, responde a pautas sócio-pragmáticas diferentes e é avaliado pelos falantes, portanto, com critérios diversificados ao longo da Hispano-América.

Fanjul (2011, p. 305) explica como o diferente interno, o traço que se afasta do modelo local de prestígio, pode receber em algumas ocasiões valorações negativas, mas esse mesmo traço pode não ser percebido de forma preconceituosa quando caracteriza a fala de outro centro de prestígio reconhecido como tal. Ele põe o exemplo do "yeismo" palatal [j] na região do Rio da Prata, que por se afastar do modelo de prestígio da capital, onde é produzido como alveopalatal [S], "pode ativar estereótipos negativos", que estão totalmente ausentes quando esse traço fonético aparece na fala de um mexicano ou de um espanhol.

Esses casos que acabamos de comentar evidenciam, por outro lado, a existência de uma enorme descontinuidade geográfica e social nos fenômenos de variação que se detectam no mundo de língua espanhola, em todos os níveis da análise gramatical. Por outro lado, na materialização desse pluricentrismo têm um grande peso as transformações que acontecem no panorama cultural durante o século XX, 
com o desenvolvimento da cultura de massas e os novos modos de produção e circulação de bens culturais. Fanjul (2011, p. 313-316) chama a atenção para um fato importante na conformação de uma ideia compartilhada de unidade linguística no mundo hispânico: a circulação eficiente de bens culturais entre diversos centros de prestígio, tais como folhetins, novelas e revistas, já desde o século XIX, e romances, filmes, seriados radiofónicos e de televisão ou música popular, no século XX. A circulação desses bens culturais permite que os falantes entrem em contato, se familiarizem e reconheçam outras variedades de espanhol diferentes daquela que eles mesmos falam.

\begin{abstract}
Assim, a partir dos anos 1940, o cinema melodramático mexicano, a canção popular espanhola, o tango argentino e os ritmos caribenhos, entre outros, serão vistos e ouvidos no continente hispano-falante todo. Esse sucesso não quer dizer que o público entendesse "tudo" o que ouvia. Sem dúvida, havia lacunas e uma fluidez de compreensão bem menor em comparação com qualquer produto local. Mas, mesmo assim, essa relativa incompreensão se integrava à fruição da obra, muitas vezes com um efeito de comicidade. (FANJUL, 2011, p. 315-316)
\end{abstract}

Como explica Moreno Cabrera (2011, p. 191), é precisamente a existência de contínuos de variedades, conformando uma corrente de solidariedade linguística em que as diferenças aparecem de forma gradual, que permite entender a unidade "natural" da língua, para além de qualquer intervenção padronizadora e sem que resulte necessário criar uma "supernorma" que se sobreponha às normas realmente existentes. $\mathrm{O}$ que garante a formação de uma ideia de unidade linguística nas representações dos falantes é, precisamente, o acesso às diversas variedades, tanto as mais próximas como as mais distantes. Pois é isso que permite reconstruir no imaginário o percurso da continuidade linguística.

De qualquer modo, o pluricentrismo hispânico sempre conviveu com a tensão permanente entre a manutenção de modelos de língua autônomos, nas diversas regiões do mundo de língua espanhola, e a obediência a uma norma prescritiva única, localizada na Espanha central. Nesse sentido, constitui um momento de extrema relevância histórica a fundação, em 1773, da Real Academia Española, que formulava como seu principal objetivo

cultivar, y fijar la puréza y elegancia de la léngua Castellana, desterrando todos los erróres que en sus vocablos, en sus modos de hablar, ò en su construcción há introducido la ignorancia, la vana afectación, el descuido, y la demasiada voluntad de innovar. (RAE)

A influência da norma prescritiva da RAE e um certo imaginário sobre a prevalência das formas ibéricas, por seu suposto "valor de origem", sempre estive- 
ram presentes, em maior ou menor medida, no ensino de língua em todo o mundo hispânico. Como vimos anteriormente, também a percepção do "perigo de fragmentação" do idioma e o temor diante de uma suposta influência desagregadora dos estrangeirismos condicionaram, em alguns momentos e lugares da América Hispânica, a obsessão por conservar, a qualquer preço, a unidade linguística com a antiga metrópole, entendida frequentemente como simples uniformidade.

Desde 1871 vão se formando academias correspondentes da espanhola em diversos países, e em 1960 essas academias passam a integrar uma associação (ASALE), sobre a qual a Real Academia Española mantém ainda uma posição de privilégio. As relações entre as academias nem sempre foram pacíficas, e a fundação de outras não correspondentes, como a Academia Nacional de Letras de Uruguay ou a Academia Argentina de Letras, encenava um conflito de autoridade normativa que, em meados do século $\mathrm{XX}$, se manifestava com bastante clareza. Nesse sentido, a Associação, de alguma maneira, reconhece uma certa autonomia das academias (o que não acontecia quando estas eram "correspondentes") e ao mesmo tempo permite que a RAE continue mantendo o seu controle sobre todas. Como explica Senz (2011, p. 211 212), é a academia da Espanha que mantém o papel de coordenação dos trabalhos padronizadores, embora se estabeleça por "consenso" a aprovação das normas e a regulação dos neologismos. A diferença financeira entre as academias também pesa no momento de estabelecer o centro em Madri. Outras desigualdades constitutivas da ASALE são instauradas pelos Estatutos: a RAE é a única academia com representação constante na Comissão Permanente e escolhe o diretor entre seus próprios membros, embora a Secretaria Geral seja ocupada efetivamente por membros das outras Academias.

Já desde antes, mas, sobretudo a partir dos anos 90, com a Espanha vivendo um momento econômico de expansão, a Academia formula uma política linguística denominada "pan-hispânica", que aparece descrita num documento da ASALE de 2004. Essa política inclui uma proposta padronizadora para o espaço internacional do espanhol, e é implementada com o apoio desigual dos governos dos países de língua espanhola e com a decidida intervenção de um conglomerado empresarial que já tinha constituído formalmente uma Fundación Pro Real Academia Española, em 1993. Os objetivos dessa fundação, segundo seus próprios estatutos, incluiriam a promoção de seus instrumentos normativos, e o financiamento de suas atividades (FUNDACIÓN PRO RAE, 1993, p. 7-8).

Como explica Valle (2007, p. 46-56), o pan-hispanismo se afasta da estrutura tradicional do nacionalismo linguístico, que relaciona uma identidade cultural compartilhada, uma língua comum e um território. No novo arranjo ideológico que jus- 
tifica a política de "unidade na diversidade" proposta pela ASALE, a língua, representada como puro instrumento de comunicação, passa a substituir os outros dois elementos do tripé. Por um lado, é apresentada desligada de toda relação cultural ou identitária, segundo os pressupostos da ideologia do anonimato (WOOLARD, 2007, p. 131-133) que sustenta a legitimidade social de línguas hegemônicas. Por outro lado, a língua constitui por si só discursivamente um "lugar de encontro", um espaço comum, para além de qualquer territorialidade nacional.

Es realmente emocionante cómo la lengua está sirviendo de lugar de encuentro y no solo como canal de comunicación. La lengua nos hace pátria común en una concordia superior. (García de la Concha, El País, 9/7/2000, apud VALLE, 2007, p. 50-51)

Estas palavras de quem então era presidente da RAE e hoje diretor do Instituto Cervantes sintetizam essa ideia, ao apresentar a língua espanhola não apenas como um instrumento de comunicação, mas como o solo de uma pátria compartilhada, de acordo com uma noção superior de "concórdia" e democracia. Nesse discurso reserva-se para a Espanha, como sublinha Valle (2007, p. 52-56), um papel central para o bem-estar e a harmonia de todos os países hispano-americanos. Fica justificada assim, ideologicamente, a projeção política e empresarial da Espanha nesse grande mercado.

Esse investimento discursivo e sua ritualização nos Congresos de la Lengua Española faz-se acompanhar de toda uma engenharia de investimento na língua como produto vendível, como recurso econômico. Dessa perspectiva, Berdugo (2001) explica a existência de um núcleo central das indústrias da língua, representado pelos serviços linguísticos, pelo ensino de espanhol como língua estrangeira e pelos materiais didáticos, que puxaria de toda uma corrente de setores econômicos: o das tecnologias da língua, em primeiro lugar, que têm um caráter estratégico; o editorial, audiovisual e musical, e, por último, o de todos os setores que possam ser identificados com a "Marca España", permitindo a abertura de mercados para produtos de todo tipo, moda, azeite, vinho...

A política pan-hispânica representa, por outro lado, a oportunidade de desenvolver uma tecnologia normativa que ofereça uma clara imagem de unidade da língua (necessária, para que ela possa cumprir esses papéis sociais a que nos estamos referindo). Nesse sentido, o reconhecimento da variação de normas de uso surge como uma necessidade que se vê compensada pelo controle normativo exercido pela RAE, que assume a missão, com base em sua autoridade histórica e utilizando os recursos mencionados, de estabelecer os limites aceitáveis dessa diversidade. 
El conocimiento de las características que presenta actualmente nuestra lengua en todos los países que integran el mundo hispánico permite llevar a cabo una auténtica política panhispánica, que recoge lo consolidado por el uso y, en los casos necesarios, se adelanta a proponer las opciones que parecen más aconsejables en aquellos puntos en los que el sistema muestra vacilación. (ASALE, 2004, p. 4)

Esse tipo de formulação se baseia numa certa indefinição (propositada?) do conceito de norma, já que o trabalho prescritivo aparece representado como um simples e neutro registro dos usos "normais", sem que se especifique, em nenhum caso, quais são os critérios adotados para delimitar exatamente o "normativo". Os instrumentos produzidos nessa perspectiva oscilam entre um prescritivismo declarado e estrito, em obras como o Diccionario Panbispánico de Dudas, e uma postura padronizadora moderada, como a que se manifesta na Nueva Gramática de la Lengua Española

A insistência na unidade da língua é sintomática, como explica José del Valle, pois tal ideia é construída através dos discursos e dos instrumentos que supostamente a descrevem:

La repetición es, por supuesto, una de las estrategias de naturalización de categorías culturalmente construidas: las celebraciones públicas de la lengua (como congresos) y los monumentos normativos que la representan (gramáticas y diccionarios) son en realidad los actos mismos que la constituyen. E igualmente, las afirmaciones de unidad aparentemente descriptivas son de hecho los actos que la crean. (VALLE, 2007, p. 94)

Por outro lado, o peso da variedade do castelhano da Espanha central nessa política normativa surge como evidência na própria ação de ensino de espanhol empreendida pelo Instituto Cervantes (IC), órgão de política cultural de ação internacional da Espanha. Segundo Hamel (2004), o IC representa essa liderança da Espanha baseada numa "política de diversidad piramidal, como lengua policéntrica pero donde un núcleo tiene más peso que los otros".

O que está em jogo ao falarmos de políticas normativas é, fundamentalmente, a questão do poder para decidir modelos de correção e articular instrumentos para a sua imposição. Também é preciso que as instituições ou agentes que propõem um padrão tenham autoridade e legitimidade reconhecidas para isso, de maneira que toda política normativa se desenvolva necessariamente numa dinâmica em que se contrapõem interesses e perspectivas.

5 Nesta obra, como explicava Elvira Arnoux no Congresso Brasileiro de Hispanistas celebrado em Salvador da Bahia em 2013, numa mesa com Ignacio Bosque, relator da Gramática, há diferenças quanto à política normativa entre as diferentes versões. O Manual apresenta uma norma menos flexível que a Gramática completa; e a versão escolar, verdadeiro instrumento padronizador para ser utilizado no ensino da língua, oferece um padrão estrito totalmente identificado com a norma da Espanha central. 


\section{PARA ALÉM DO PAN-HISPANISMO: CONCORRÊNCIA COMERCIAL E DISPUTA PELA SOBERANIA IDIOMÁTICA}

O espaço político do espanhol no mundo está em permanente mutação, num jogo dinâmico, como dizíamos, de confrontos e de solidariedades. Isso não deve parecer estranho, dado que o conflito e a dissensão são constitutivos de todo espaço político. A crise econômica na Espanha e os sucessivos recortes orçamentários em políticas públicas provocaram nos últimos anos uma evidente desaceleração das ações de expansão ideadas pelos agentes da política linguística do espanhol ${ }^{6}$. Por outro lado, novas iniciativas, muitas delas calcadas no modelo de ação inaugurado pela própria Espanha, surgem em diversos pontos do mundo hispânico.

Trilhando o caminho inaugurado por empresas e instituições espanholas, por exemplo, encontramos ações de investimento nas indústrias da língua, e, sobretudo, no seu núcleo central, o ensino como língua estrangeira, em países como a Colômbia. O Instituto Caro y Cuervo desenhou uma campanha para promover o país como centro de ensino para estrangeiros com o lema: "Para aprender el mejor español del mundo, ila respuesta es Colombia!" (INSTITUTO CARO Y CUERVO, 2013). Curiosamente, essa iniciativa se apropria do discurso e da estratégia espanholas, pois no site do Instituto são utilizados dados elaborados pelo IC sobre o espanhol no mundo, como argumentos para justificar o papel da Colômbia no mercado internacional de ensino desse idioma. Em outras palavras, com essa ação, esse país americano disputa sua parte no mercado do ensino da língua utilizando instrumentos da própria Espanha e radicalizando o discurso da centralidade normativa. Assume, assim, um discurso extremamente purista e preconceituoso que a Espanha, por seu passado histórico de dominação política sobre a América, nunca poderia explicitar (embora esteja implícito, como vimos, em sua política normativa) sem entrar em confronto político direto com os países americanos.

Também a Argentina tem realizado um forte investimento no turismo idiomático, como recurso econômico e de intercâmbio cultural. O I Congreso Internacional de Turismo Idiomático, celebrado em Córdoba, Argentina, em 2010, adotava o tema do espanhol como língua estrangeira como uma oportunidade para o desenvolvimento turístico sustentável, e chamava a atenção para o valor turístico, econômico e cultural da língua espanhola. Além da Argentina, onde se celebrou em duas ocasiões, outra edição do congresso foi celebrada no Chile, e a quarta ocorrerá em São Paulo, em 2014. Esse tipo de evento, destinado a agentes de viagens, hotelaria, estudantes

\footnotetext{
6 Essa expansão se orienta no continente americano em direção às duas grandes fronteiras linguísticas do castelhano, a do português pelo sul (Brasil) e a do inglês pelo norte (USA).
} 
e professores de turismo, assim como a professores de língua e diretores de centros de idiomas e entidades públicas relacionadas ao turismo idiomático, parece estar concebido em termos regionais, como política de integração orientada tanto ao espanhol quanto ao português como línguas da América do Sul.

Quanto à política normativa, iniciativas concretas começam a configurar efetivamente um panorama em que é possível identificar diversos centros padronizadores. $\mathrm{Na}$ Argentina e no México foram produzidos dicionários integrais de espanhol que, longe de constituírem dicionários de "argentinismos" ou de "mexicanismos", são instrumentos que abordam o idioma desde seus próprios centros, sem se limitarem a ser repertórios de diferenças lexicais a respeito do vocabulário da antiga metrópole. Essa abordagem dialetalista do espanhol americano pertence, contrariamente, à tradição acadêmica espanhola. Numa resenha do Diccionario de Americanismos, publicado pela ASALE, em 2010, sob direção de Humberto López Morales, Luis Fernando Lara (2012), diretor do longo projeto de pesquisa que culminou com a realização do Diccionario del Español de México, critica esse desejo acadêmico de elaborar um dicionário do "espanhol da América", concebido como um vocabulário que se contrapõe ao da Península, que seria categorizado como "espanhol geral" ou "neutro".

Lara critica os pressupostos teóricos e científicos do Diccionario de Americanismos. O que aparece definido como descritivismo não seria mais, na realidade, do que uma espécie de "não prescritivismo", pois não se baseia em pesquisas amplas sobre os usos reais da língua no continente americano. Mas, sobretudo, o autor questiona os princípios ideológicos que sustentam uma obra com essas características:

\begin{abstract}
Cuestionamos el planteamiento diferencial que lo sustenta, en cuanto supone que el vocabulario del «español general» corresponde, en su mayor parte, al peninsular, y dentro de éste, al que los diccionarios de la Academia Española han venido reuniendo desde hace tres siglos, en tanto que los americanismos — como también los andalucismos, murcianismos, canarismos, etc.- solo pueden constituir un vocabulario periférico, todavía marcado en muchos lugares de España e Hispanoamérica como proclive al barbarismo y siempre objeto de necesaria corrección. (LARA, 2012, p. 352)
\end{abstract}

O linguista mexicano atribui essa perspectiva colonialista, historicamente, à dinastia dos bourbons, herdeira do centralismo francês, pois anteriormente, no Diccionario de Autoridades, elaborado entre 1713 e 1729, não se realizava esse tipo de distinção entre o vocabulário utilizado pelas elites culturais espanholas e americanas.

Mas a mais contundente reação ao centralismo normativo imposto pela tradição acadêmica espanhola é o recente manifesto "Por una soberanía idiomática", publicado em Buenos Aires, em setembro de 2013. Duas propostas concretas cul- 
minam o manifesto: a criação de um Instituto Borges, e a formação de um foro de debates sobre os caminhos políticos da língua castelhana no Museo del libro y de la lengua da Biblioteca Nacional. Esse museu, por outro lado, constitui em si um evento glotopolítico de indubitável importância, pois, seguindo os passos do Museu da Língua Portuguesa de São Paulo, constrói uma memória própria sobre a história e os destinos da língua castelhana no continente americano.

O manifesto começa denunciando o espírito centralista da política normativa da RAE, constatando que as instituições da língua são "globalizadoras cuando piensan el mercado y monárquicas cuando tratan la norma", e situando a própria iniciativa na tradição nacional argentina de reivindicação de uma soberania linguística. De qualquer modo, essa reivindicação não se limita à posição estritamente nacional, mas aborda a questão da língua de um ponto de vista regional, como instrumento de integração política e cultural dos países da América do Sul. Nesse contexto, pretende-se a "valoración política de la heterogeneidad más que [el] festejo mercantil de la diversidad", defendendo-se a criação de foros de debate que discutam a dimensão linguística e cultural das industrias audiovisuais, das estratégias educativas ou do campo literário.

Entendendo que a Espanha empreendeu um projeto de impulso estratégico da língua com vistas ao próprio desenvolvimento econômico, destinado à venda da "marca España", os intelectuais que assinam o manifesto não questionam o direito desse país a ter sua própria política de Estado em relação à língua, mas se perguntam o porquê da ausência de alguma política nesse mesmo sentido por parte da Argentina. Na situação atual apenas a Espanha usufruiria desse bem compartilhado que é o idioma.

A constatação da necessidade de uma política argentina para a língua não implicaria, porém, segundo o manifesto, a imitação dos procedimentos uniformizadores nem mercadológicos utilizados pela Espanha. As políticas para a língua que esse documento propõe construir teriam um caráter ao mesmo tempo nacional e regional. Daí, em parte, o simbolismo do nome Borges, o autor mais internacional da língua espanhola, o "Cervantes del siglo XX".

O termo "soberania" procede do campo da teoria política, que nasceu, no século XVI, da teoria do Estado de Jean Bodin, que a definia como poder ilimitado e perpétuo que responde apenas à lei natural e à lei divina. É Rousseau quem transfere esse conceito do monarca para o povo. Como explica Agamben (2004), desenvolvendo as teorias de Carl Schmitt do ponto de vista jurídico, soberano é aquele que decide sobre o estado de exceção, que decide sobre a norma e a sua suspensão, determinando zonas de anomia que, contudo, mantêm relação com a ordem jurí- 
dica. O uso do termo "soberania" no manifesto coloca de forma rotunda a questão da língua no âmbito das relações de poder e interroga, provocadoramente, sobre os próprios limites dessa entidade impositiva que é a língua e sobre o seu controle.

A pergunta sobre a língua e o poder deve ocupar, de fato, a atenção de todos aqueles que, no jogo de interesses que constituem as dinâmicas políticas, pretendem(os) lutar por maiores espaços de igualdade e reconhecimento para os falantes. Resta saber (e não é um desafio pequeno) em que medida os construtos envolvidos nas políticas de línguas permitem construir relações e práticas efetivamente mais igualitárias.

\section{REFERÊNCIAS BIBLIOGRÁFICAS}

AGAMBEN, G. (2004). Estado de exceção. Homo sacer II. São Paulo: Boitempo Editorial.

ALFÓN, F. (2008). Los orígenes de las querellas sobre la lengua en Argentina. In: Horacio González (comp.). Beligerancia de los idiomas. Un siglo y medio de discusión sobre la lengua latinoamericana. Buenos Aires: Colihue, p. 43-78.

ALONSO, A. (1979). Castellano, español, idioma nacional. Historia espiritual de tres nombres. Buenos Aires: Losada.

ANDERSON, B. (2008). Comunidades imaginadas: reflexões sobre a origem e a difusão do nacionalismo. São Paulo: Companhia das Letras.

ARNOUX, E. N. de (2008). Los discursos sobre la nación y el lenguaje en la formación del Estado (Chile, 1842-1862). Estudio glotopolítico. Buenos Aires: Santiago Arcos Editor/SEMA.

ASALE (2004). La nueva política lingüística panbispánica. Madri: Real Academia Española.

BERDUGO, Ó. (2001). El español como recurso económico: anatomía de un nuevo sector. Actas del II Congreso Internacional de la lengua española. Centro virtual Cervantes. Disponível em http://cvc.cervantes.es/obref/congresos/valladolid/ponencias/activo del espanol/1 la industria del espanol/berdugo o.htm. Acesso em 12 de novembro de 2013

CALVET, L-J. (2004). Por unba ecoloxía das línguas no mundo. Santiago de Compostela: Laiovento.

(2012). Nouvelles perspectives sur les politiques linguistiques: les poids des langues. Gragoatá 32, Política e planificação linguística: 55-74.

CAMÕES, L. de (1988). Os Lusíadas. Lisboa: Biblioteca Ulisseia de autores portugueses.

CASANOVA, P. (2002). A República Mundial das Letras. São Paulo: Estação Liberdade.

COSERIU, E. (1979). "Sistema, norma e fala" [1952]. Teoria da Linguagem e Linguistica Geral: cinco estudos. Rio de Janeiro/São Paulo: Presença/EDUSP, p. 13-85.

CRYSTAL, D. (2006). A revolução da linguagem. Rio de Janeiro: Jorge Zahar Editor.

DE GRANDA, G. (1994). Español de América, español de África y bablas criollas bispánicas. Cambios, contactos y contextos. Madri: Gredos. 
FANJUL, A. P. (2011). "Policêntrico" e "Pan-hispânico". Deslocamentos na vida política da língua espanhola. In: Xoán Carlos Lagares e Marcos Bagno (orgs.). Políticas da norma e conflitos linguísticos. São Paulo: Parábola, p. 299-332.

FERNÁNDEZ, M. (2007). De la lengua del mestizaje al mestizaje de la lengua: reflexiones sobre los limites de una nueva estrategia discursiva. In: José del Valle (ed.). La lengua, ¿patria común? Ideas e ideologías del español. Madri/Frankfurt am Main: Iberoamericana/ Vervuert, p. 57-80.

FONTANELLA DE WEINBERG, M. B. (1992). El español de América. Madri: Mapfre.

FRAGO GARCÍA, J. A. (1999). Historia del español de América. Madri: Gredos.

GUISAN, P. (2011). A criação de uma norma padrão em francês: entre planejamento político e mito. In: Xoán Carlos Lagares e Marcos Bagno (orgs.). Políticas da norma e conflitos linguísticos. São Paulo: Parábola, p. 129-152.

HAMEL, R. E. (2004). Las cuatro fronteras de la identidad lingüística del español: lengua dominante y dominada, lengua fronteriza y lengua internacional. Actas del III Congreso Internacional de la lengua española. Centro Virtual Cervantes Disponível em http://cvc. cervantes.es/obref/congresos/rosario/mesas/hamel r.htm. Acesso em 12 de novembro de 2013.

LAGARES, X. C. (2011). Minorias linguísticas, políticas normativas e mercados. Uma reflexão a partir do galego. In: Xoán Carlos Lagares e Marcos Bagno (orgs.). Políticas da norma e conflitos linguísticos. São Paulo: Parábola, p. 169-192.

LARA, L. F. (2012). Resenha de Diccionario de Americanismos.Panace@, vol. XIII, nº 36, segundo semestre de 2012: 352-355.

LE BRETON, J-M. (2005). Reflexões anglófilas sobre a geopolítica do inglês. In: Yves Lacoste (org) e Kanavillil Rajagopalan. A geopolítica do inglês. São Paulo: Parábola, p.1226.

MALMBERG, B. (1970). La América bispanobablante. Unidad y diferenciación del castellano. Madri: Ediciones Istmo.

MONTEAGUDO, H. (2013). A invenção do monolinguismo e da língua nacional. Gragoatá 32, Política e planificação linguística: 43-54.

MORENO CABRERA, J. C. (2011). "Unifica, limpia y fija". La RAE y los mitos del nacionalismo linguístico español. In: Silvia Senz e Montserrat Alberte (orgs.). El dardo en la palabra. Esencia y vigência de las academias de la lengua española. Vol. 1. Barcelona: Melusina, p. 157-314.

NIEDEREHE, H-J. (1985). Alfonso el Sabio y la fisionomía lingüística de la Península Ibérica de su época. La Lengua y la Literatura en tiempos de Alfonso X. Actas del congreso internacional. Murcia, 5-10 de marzo de 1984. Murcia: Universidad de Murcia, p. 415-431.

OLIVEIRA, G. M. de (2013). Um Atlântico ampliado: o português nas políticas linguísticas do século XXI. In: Luiz Paulo da Moita Lopes (org.). O português no século XXI. Cenário geopolítico e sociolinguístico. São Paulo: Parábola, p. 53-73.

POCHE, B. (1989). A construção social da língua. In: G. Vermes e J. Boutet (orgs.). Multilinguismo. Campinas: Editora da Unicamp, p. 57-88. 
REY, A. (2001). Usos, julgamentos e prescrições linguísticas. In: Marcos Bagno (org.). Norma linguística. São Paulo: Edições Loyola.

SENZ, S. (2011). Una, grande y (esencialmente) uniforme. La RAE en la conformación y expansión de la "lengua común". In: Silvia Senz e Montserrat Alberte (orgs.). El dardo en la palabra. Esencia y vigência de las academias de la lengua española. Vol. 1. Barcelona: Melusina, p. 9-302.

SUBIRATS, E. (2006). Siete tesis contra el Hispanismo. In: Alai Garcia Diniz (org.). Hispanismo 2004. Literatura Espanbola. Florianópolis: Universidade Federal de Santa Catarina, p. 15-36.

VALLE, J. del. (2007). La lengua, patria común: la bispanofonía y el nacionalismo panhispánico. In: José del Valle (ed.). La lengua, ¿patria común? Ideas e ideologías del español. Madri/ Frankfurt am Main: Iberoamericana/Vervuert, p. 31-56.

. (2013). A Political History of Spanish. The Making of a Language. Cambridge: Cambridge University Press.

WOOLARD, K. A. (2007). La autoridad linguística del español y las ideologias de la autenticidad y del anonimato. In: José del Valle (ed.). La lengua, cpatria común? Ideas e ideologías del español. Madri/Frankfurt am Main: Iberoamericana/Vervuert, p. 129-142.

\section{Documentos}

FUNDACIÓN PRO RAE (1993). Estatutos. Disponível em http://fprorae.es/sites/default/ files/Estatutos fprorae21red1.pdf. Acesso em 12 de novembro de 2013

INSTITUTO CARO Y CUERVO. http://www.caroycuervo.gov.co/press-release/para-aprender-el-mejor-espa\%C3\%B1ol-del-mundo-\%C2\%A1la-respuesta-es-colombia. Acesso em 12 de novembro de 2013.

MANIFIESTO: "Por una soberanía idiomática". http://soberaniaidiomatica.blogspot.com. br/2013/09/por-una-soberania-idiomatica.html. Acesso em 12 de novembro de 2013.

RAE: Real Academia Española. www.rae.es. Acesso em 12 de novembro de 2013.

Recebido: $13 / 07 / 2013$

Aceito: 21/11/2013 